\title{
Aesthetic scrotal reconstruction following extensive Fournier's gangrene using bilateral island pedicled sensate anterolateral thigh flaps: A case report
}

\author{
Joseph H. Dayan, MD; Emily M. Clarke-Pearson, MD; Erez Dayan, MD; Mark L. Smith, MD \\ Beth Israel Medical Center, New York, NY
}

Cite as: Can Urol Assoc J 2014;8(1-2):el 14-7. http://dx.doi.org/10.5489/cuaj.1384 Published online February 12, 2014.

\section{Abstract}

Achieving an aesthetic appearance of the scrotum after extensive Fournier's gangrene is a reconstructive challenge. Testicular coverage is often prioritized over scrotal cosmesis due to the comorbidities typically seen in this patient population. We describe our treatment of a young, healthy male with extensive Fournier's gangrene, with loss of the scrotum. Bilateral neurotized anterolateral thigh flaps were used to achieve a sensate and aesthetically acceptable result.

\section{Introduction}

Achieving an aesthetic appearance of the scrotum after extensive Fournier's gangrene is a reconstructive challenge. Testicular coverage is often prioritized over scrotal cosmesis due to the comorbidities typically seen in this patient population. ${ }^{1-3}$ Several techniques have been described to provide durable coverage, but do not necessarily provide an ideal cosmetic result. ${ }^{4-15}$ We describe our treatment of a young, healthy male with extensive Fournier's gangrene with loss of the scrotum. Bilateral neurotized anterolateral thigh (ALT) flaps were used to achieve a sensate and aesthetically acceptable result.

\section{Case report}

A 27-year-old, otherwise healthy, male presented in septic shock secondary to Fournier's gangrene. Three days prior, he had sought treatment for a small perirectal abscess, which was managed with drainage and outpatient oral antibiotics. The infection evolved into necrotizing fasciitis involving the entire scrotum, cord structures, perineum, peri-rectal space and retroperitoneum. He was taken emergently to the oper- ating room for debridement and creation of a suprapubic cystostomy and colostomy for urinary and fecal diversion.

During the ensuing 4 weeks, the patient was treated with multiple debridements, wound care and intravenous antibiotics. Dartos fascia and portions of the tunica albuginea were debrided. Reconstructive options, including skin grafting, burying the testes in the thigh and a variety of flaps, were discussed with the patient. He was most concerned with his aesthetic outcome, sexual function and scrotal sensation.

\section{Operative technique}

Prior to reconstruction, the defect measured $22 \times 20 \mathrm{~cm}$ $\left(440 \mathrm{~cm}^{2}\right)$, with exposure of the pubis, spermatic cords, testes and perineum (Fig. 1). Reconstruction was performed with bilateral sensate pedicled ALT flaps innervated by the lateral femoral cutaneous nerves. Bilateral tunnels were created beneath the rectus femoris muscle and medial thigh skin connecting the donor site and the scrotal defect. Each flap was then passed through the tunnel and into the defect (Fig. 2). The lateral femoral cutaneous nerves were harvested with the flaps, and neurorrhaphy to the genital branch of the genito-femoral nerve was performed bilaterally. The flaps were approximated in the midline to mimic the scrotal raphe. The right, and most of the left, donor sites were closed primarily, with the remainder $(10 \times 4 \mathrm{~cm})$ of the left donor site covered with a full-thickness skin graft harvested from remnants of the ALT flaps, following trimming and insetting.

\section{Results}

Both flaps healed uneventfully, aside from an area of frictionrelated epidermolysis on the right hemiscrotum, which left a patchy area of persistent hypopigmentation. Both flaps had hair growth and the patient reported satisfactory scrotal sensation, although this was not evaluated objectively (Fig. 3). The donor sites healed without complication and returned to full function. 


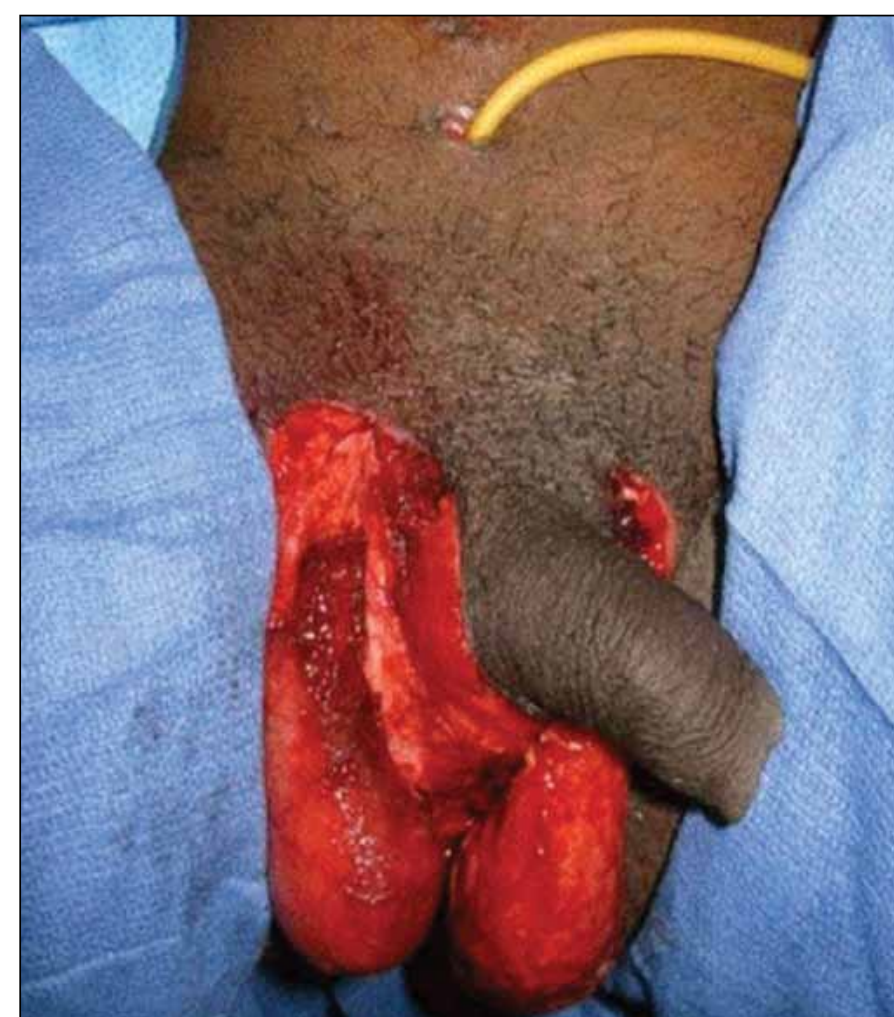

Fig. 1. Fournier's gangrene resulting in a $22 \times 20-\mathrm{cm}$ defect with exposed testes base of penis, cord structures, and perineum following multiple debridements.

Six months postoperatively, the patient felt his scrotum was too thick and complained of tethering at the base of the ventral side of his penis. Liposuction of the neo-scrotum was effectively used to debulk the flaps. In addition, a single V-Y advancement at the junction of both hemi-scrotal flaps was performed to release the tethering at the base of the penis. At 1 year postoperatively, the patient reported satisfactory sexual function, micturition and scrotal sensation (Fig. 4, Fig. 5). His one remaining complaint was that his penis appeared somewhat shorter. This is a result of the increased thickness of the ALT flaps, compared to native scrotal skin, at its junction with the base of the penis. We offered to recess the flaps and apply a full-thickness skin graft to the base of his penis. He is currently considering this option.

\section{Discussion}

Fournier's gangrene is a life-threatening condition that usually affects patients of advanced age with comorbidities, such as diabetes, obesity and immunosuppression..$^{1-3,16}$ Mortality rates between $4 \%$ and $46 \%$ have been reported. ${ }^{1-3,16}$ Early aggressive serial debridement and intravenous antibiotics, followed by some form of durable wound coverage, is standard therapy. ${ }^{1-3,14,15,17}$

Because most patients with Fournier's gangrene are older with comorbidities, comesis may not be a primary consid-

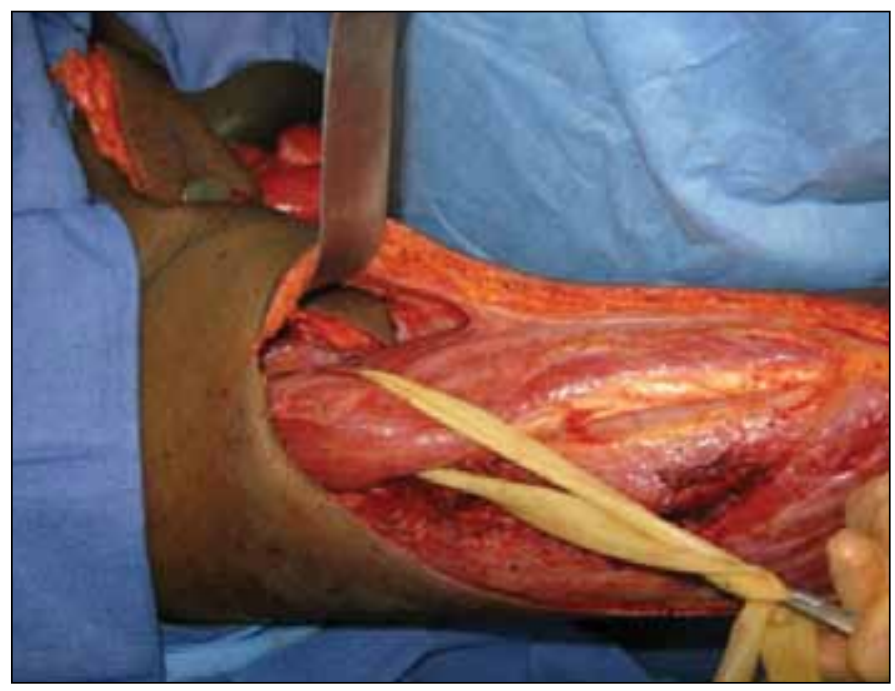

Fig. 2. Anterolateral thigh flap tunneled beneath the rectus femoris. The lateral femoral cutaneous nerves were harvested with each flap and were coapted to the genital branch of the genitofemoral nerve.

eration in the reconstruction. As a young, healthy male, our patient was concerned about his appearance, sensation and sexual function. While skin grafting can provide an acceptable result in purely scrotal defects, in this case it would have appeared unsightly, as the hairless, skeletonized contour of the pubic region, spermatic cords and testes would be evident. ${ }^{6,18,19}$ Muscle flaps, such as gracilis, covered by skin grafts are an alternative, but lack sensation; if the muscle flaps are innervated to preserve bulk, they may cause unwanted contraction; conversely, if they are denervated, they can atrophy over time. ${ }^{14,20-24}$

Additionally, there may be concern regarding sperm production in the setting of skin grafting. ${ }^{18,25-28}$ One recent study by Demir and colleagues compared testicular function following groin flap coverage versus skin graft coverage in a rat model. This study demonstrated diminished function in the skin graft group. ${ }^{25}$ Our patient had not undergone testing for sperm function at this time.

Sensate fasciocutaneous flaps based on the pudendal neurovascular pedicle, such as the Malaga and Singapore flaps, are an alternative..$^{9,20,22}$ However, coverage of a $20 \times 22-\mathrm{cm}$ defect would be challenging with these techniques. Additionally, this patient's wound tracked posteriorly around the rectum and into the retroperitoneum, with undermining on the left where the pedicle emerges. Few regional fasciocutaneous flaps can match the extensive coverage the ALT flap can provide for resurfacing a defect of this size.

Coverage of scrotal defects using a single ALT lap was first described by $\mathrm{Yu}$ and colleagues. ${ }^{24,29}$ In the patient presented in this report, bilateral neurotized pedicled island ALT flaps were chosen because of the potential to harvest a large amount of sensate, hair-bearing skin. The flaps inset easily into the defect and provide a median scrotal raphe at 


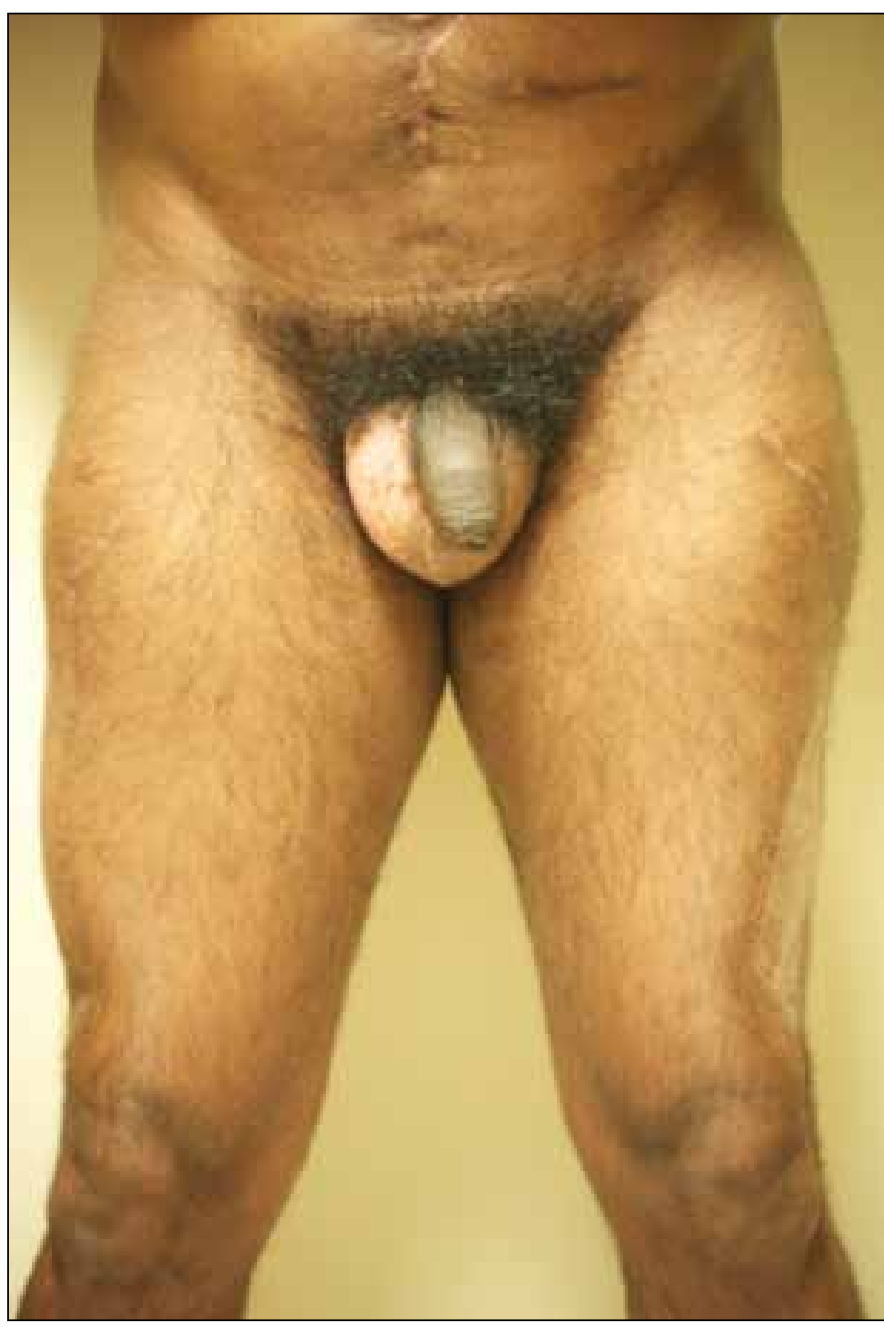

Fig. 3. Postoperative result at 12 months following revision with liposuction and $\mathrm{V}-\mathrm{Y}$ advancement at the ventral side of the penis.

their junction. The fascia lata may act as a replacement for Dartos fascia, although this is probably clinically insignificant. Harvesting the flaps with the lateral femoral cutaneous nerve allows neurotization of the flaps; however, we cannot confirm its value as it was only subjectively assessed. Even with the current modalities available, measuring meaningful erogenous sensation in the scrotum is difficult and therefore the added value of neurotization remains unclear. ${ }^{30}$ Our patient is sexually active and states that his scrotal sensation feels normal. The patient is satisfied with his overall appearance, but will require tattooing to camouflage the area of hypopigmentation.

\section{Conclusion}

Bilateral neurotized ALT flaps can provide hair-bearing, sensate coverage of scrotal contents, and a satisfactory cosmetic result in patients with Fournier's gangrene of the scrotum.

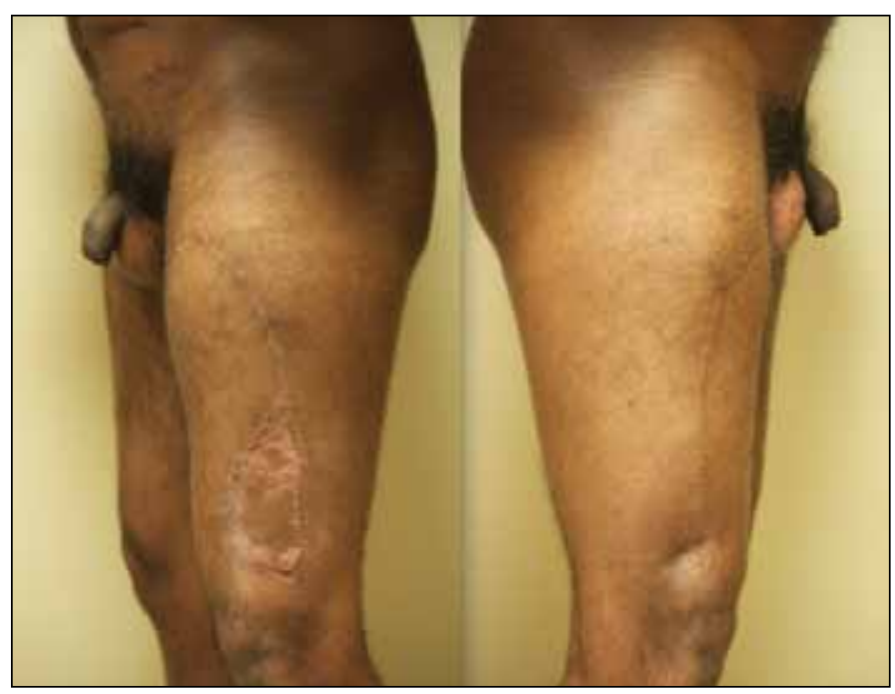

Fig. 4. Donor site.

Competing interests: Dr. X, Dr. X and Dr. X all declare no competing financial or personal interests.

This paper has been peer-reviewed.

\section{References}

1. Fajdic JN, Gotovac, Hrgovic z. Fournier gangrene: Our approach and patients. Urol Int 2011;87:186-91. http://dx.doi.org/10.1159/000327510

2. Jeong HJ, Park SC, Seo IY, et al. Prognostic factors in Fournier gangrene. Int J Urol 2005;12:1041-4. http://dx.doi.org/10.1111/i.1442-2042.2005.01204.x

3. Yanar $\mathrm{H}$, Taviloglu $\mathrm{K}$, Ertekin C, et al. Fournier's gangrene: risk factors and strategies for management. World J Surg 2006;30:1750-4. http://dx.doi.org/10.1007/s00268-005-0777-3

4. Hsu H, Lin CM, Sun TB, et al. Unilateral gracilis myofasciocutaneous advancement flap for single stage reconstruction of scrotal and perineal defects. J Plast Reconstr Aesthet Surg 2007;60:1055-9. http:// dx.doi.org/10.1016/i.bips.2006.09.005

5. Lee YT, Lee JM. Gracilis myocutaneous flap for the coverage of an extensive scrotoperineal defect and protection of the ruptured urethra and testes. Yonsei Med J 1990;31:187-91.

6. Tan BK, Rasheed MZ, Wu WT. Scrotal reconstruction by testicular apposition and wrap-around skin grafting. J Plast Reconstr Aesthet Surg 2011;64:944-8. http://dx.doi.org/10.1016/j.bjps.2010.11.013

7. Karsidag $S$, Akcal $A$, Sivvan $S S$, et al. Perineoscrotal reconstruction using a medial circumflex femoral artery perforator flap. Microsurgery 2011;31:116-21. http://dx.doi.org/10.1002/micr.20839

8. Kayikcioglu A. A new technique in scrotal reconstruction: Short gracilis flap. Urology 2003;61:1254-6. http://dx.doi.org/10.1016/S0090-4295(03)00158-4

9. Hallock GG. Scrotal reconstruction following Fournier gangrene using the medial circumflex femoral artery perforator flap. Ann Plast Surg 2006;57:333-5. http://dx.doi.org/10.1097/01. sap.0000218505.13232.1b

10. Ellabban MG, Townsend PL. Single-stage muscle flap reconstruction of major scrotal defects: Report of two cases. Br J Plast Surg 2003:56:489-93. http://dx.doi.org/10.1016/S0007-1226(03)00178-4

11. El-Khatib HA. V-Y fasciocutaneous pudendal thigh flap for repair of perineum and genital region after necrotizing fasciitis: modification and new indication. Ann Plast Surg 2002;48:370-5. http://dx.doi. org/10.1097/00000637-200204000-00006

12. Coskunfirat OK, Koray 0 , Uslu A, et al. Superiority of medial circumflex femoral artery perforator flap in scrotal reconstruction. Ann Plast Surg 201 1;67:526-30. http://dx.doi.org/10.1097/SAP.0b013e318208ff00

13. Hirshowitz B, Moscona R, Kaufman T, et al. One-stage reconstruction of the scrotum following Fournier's syndrome using a probable arterial flap. Plast Reconstr Surg 1980;66:608-12. http://dx.doi. org/10.1097/00006534-198010000-00021

14. Chen SY, Fu JP, Chen TM, et al. Reconstruction of scrotal and perineal defects in Fournier's gangrene. J Plast Reconstr Aesthet Surg 201 1;64:528-34. http://dx.doi.org/10.1016/i.bjps.2010.07.018 
15. Chen SY, Fu JP, Wang $C H$, et al. Fournier gangrene: a review of 41 patients and strategies for reconstruction. Ann Plast Surg 2010;64:765-9. http://dx.doi.org/10.1097/SAP.0b013e3181ba5485

16. Corcoran AT, Smaldone MC, Gibbons EP, et al. Validation of the Fournier's gangrene severity index in a large contemporary series. J Urol 2008;180:944-8. http://dx.doi.org/10.1016/i.juro.2008.05.021

17. Horta $R$, Cerqueira $M$, Marques $M$, et al. Fournier's gangrene: From urological emergency to plastic surgery [in Spanish]. Actas Urol Esp 2009;33:925-9. http://dx.doi.org/10.1016/S0210-4806(09)72884-0

18. Sun $G C$, Zhong $A G, H e W$, et al. Reconstruction of the external genitals and repair of skin defects of the perineal region using three types of lateral groin flap. Ann Plast Surg 1990;24:328-34. http://dx.doi. org/10.1097/00000637-199004000-00005

19. Campbell RM. Dermatome grafting of the totally denuded testes. Plast Reconstr Surg 1957;19:509-13. http://dx.doi.org/10.1097/00006534-195706000-00007

20. Karacal N, Livaoglu $M$, Kutlu N, et al. Scrotum reconstruction with neurovascular pedicled pudendal thigh flaps. Urology 2007;70:170-2. hittp://dx.doi.org/10.1016/i.urology.2007.03.049

21. Ng RW, Chan JYW, Mok V, et al. Clinical use of a pedicled anterolateral thigh flap. J Plast Reconstr Aesthet Surg 2008;61:158-64. http://dx.doi.org/10.1016/i.bjps.2007.10.028

22. Wang TN, Whetzel T, Mathes S, et al. A fasciocutaneous flap for vaginal and perineal reconstruction. Plast Reconstr Surg 1987;80:95-103. http://dx.doi.org/10.1097/00006534-198707000-00015

23. Wang $X$, Qiao $Q$, Burd A, et al. Perineum reconstruction with pedicled anterolateral thigh fasciocutaneous flap. Ann Plast Surg 2006;56:151-5. http://dx.doi.org/10.1097/01.sap.0000189685.82616.59
24. $Y_{U}$ P, Sanger JR, Matloub HS, et al. Anterolateral thigh fasciocutaneous island flaps in perineoscrotal reconstruction. Plast Reconstr Surg 2002;109:610-6; discussion 617-8. http://dx.doi. org/10.1097/00006534-200202000-00030

25. Demir Y, Aktepe F, Kandal S, et al. The effect of scrotal reconstruction with skin flaps and skin grafts on testicular function. Ann Plast Surg 2012;68:308-13. http://dx.doi.org/10.1097/SAP.0b013e318214534f

26. Wang $D$, Zheng $H$, Deng $F$, et al. Spermatogenesis after scrotal reconstruction. Br J Plast Surg 2003;56:484-8. http://dx.doi.org/10.1016/S0007-1226(03)00187-5

27. Wang D, Wei $Z$, Sun $G$, et al. Thin-trimming of the scrotal reconstruction flap: long-term follow-up shows reversal of spermatogenesis arrest. J Plast Reconstr Aesthet Surg 2009;62:e455-6. http://dx.doi. org/10.1016/i.bips.2008.06.014

28. Culp DA, Huffman WC. Temperature determination in the thigh with regard to burying the traumatically exposed testis. J Urol 1956;76:436-8.

29. Song $\mathrm{YG}$, Chen $\mathrm{GZ}$, Song YL. The free thigh flap: a new free flap concept based on the septocutaneous artery. Br J Plast Surg 1984;37:149-59. http://dx.doi.org/10.1016/0007-1226(84)90002-X

30. Maguina P, Paulius KL, Kale S, et al. Medial thigh fasciocutaneous flaps for reconstruction of the scrotum following Fournier gangrene. Plast Reconstr Surg 2010;125:28e-30e. http://dx.doi.org/10.1097/ PRS.0b013e3181c2a292

Correspondence: Dr. Erez Dayan, Beth Israel Medical Center, New York, NY; erezdayan1@gmail.com 